\title{
SIEMPRE FUIMOS EL OTRO RACIALIZACIÓN, POLIFONÍA E HISTORIA DE LA MÚSICA
}

\author{
WE HAVE ALWAYS BEEN THE OTHER \\ RACIALISM, POLYPHONY AND HISTORY OF MUSIC
}

Leticia Zucherino

zuclet@hotmail.com

Guido Dalponte

guidalponte@hotmail.com

Historia de la Música I. Instituto de Investigación en Producción y Enseñanza del Arte Argentino y Latinoamericano. Facultad de Bellas Artes.

Universidad Nacional de La Plata. Argentina

Recibido: 21/12/2017 | Aceptado: 11/4/2018

\section{RESUMEN}

Se suele considerar natural que el estudio de la polifonía constituya una parte central de la formación musical. Este supuesto, que encierra un mecanismo altamente sofisticado de dominación cultural, cala en la enseñanza musical en todos los niveles, en la investigación y en la práctica. La sofisticación del compositor, sujeto privilegiado de la historiografía tradicional de la música, depende de cuánto y cuán bien domine el lenguaje polifónico, sus procedimientos esquematizados y la especulación analítica. La historia de la música puede encontrar en el estudio de fuentes alternativas a la partitura, registros de prácticas que re ordenen el relato hegemónico.

\section{PALABRAS CLAVE}

Historiografía musical; música popular; polifonía; fuentes históricas

\section{ABSTRACT}

It is usually considered notural that the study of polyphony is a central part of the musical formation. This assumption, which contains a highly sophisticated mechanism of cultural domination, digs into music education at all levels, both in research and in practice. The quality of the composer, privileged subject in the traditional historiography of music, depends on how much and how well he or she dominates the polyphonic language, its schematized procedures and analytical speculation. The history of music can find in the study of sources alternatives to the score, records of practices that reorder the hegemonic narrative.

\section{KEYWORDS}

Musical historiography; popular music; poliphony; primary sources 
A simple vista, hablar de polifonía en una clase de Historia de la Música parece ser indispensable. Organizadora del discurso evolucionista tradicional, responsable del carácter especulativo y reglado de la composición, base fundamental para la valoración de la complejidad de la obra musical, fundamento principal de la especulación analítica. La polifonía rige ampliamente sobre los otros aspectos técnico-procedimentales y la historia de la música es, en parte, responsable en el establecimiento de esta premisa. De este modo, ambos comienzos, el relato del surgimiento de la polifonía y los inicios de la tradición musical occidental, son inseparables.

La preocupación por establecer los orígenes, puntos claros de partida, en la historia de la música con perspectiva positivista ha llevado a la afirmación de que la polifonía apareció en el seno mismo de la Edad Media:

Entre los siglos V y IX, los pueblos de la Europa occidental y septentrional se convirtieron al cristianismo y a las doctrinas y ritos de la iglesia cristiana [...].

Este proceso evolutivo coincidió con el surgimiento del canto monódico profano y con los primeros experimentos en materia de polifonía (Grout, 1980, p. 79).

Así, las prácticas polifónicas en el canto cristiano se configuran como génesis de una técnica que, paulatinamente, va a complejizarse desde ese momento hasta el punto máximo del desarrollo del lenguaje armónico-tonal a finales del siglo XIX. La concepción del canto cristiano como iniciático no es una afirmación aplicable solo a este parámetro musical, sino que es un repertorio que soporta el peso de ser donde se fundan las bases de la teoría musical y, a partir del siglo IX, de la notación musical, entre otras cosas.

El canto cristiano, como dice Leo Treitler (1991), cumple una doble función: por un lado, reclama ser el heredero de la música de la Grecia antigua, que servirá de modelo para la cultura occidental moderna y, por otro, a partir de ser la primera tradición musical registrada en partituras, es usado inclusive "para validar esas características como criterio esencial, para reconocer lo que hay de europeo en toda música y tal vez de mayor importancia, lo que no hay de extra-europeo»' (p. 280).

¿Es posible pensar, entonces, en músicas polifónicas por fuera de los repertorios canónicos de la historia de la música? Si pensamos en la polifonía como simultaneidad de frecuencias distintas en una música, el origen se remonta mucho más allá de cualquier registro que haya llegado hasta nuestros días. Es imposible fechar el momento en que las primeras comunidades cantaron en grupo, se acompañaron, ordenaron el ruido por primera vez; en todo caso, ¿qué sentido tendría hacerlo? Claramente ninguno, al menos a los fines prácticos de este artículo. La búsqueda del origen de

1 «Validated those qualities as the essential touchstone for recognizing what was European in music - and, perhaps of greater importance, what was not non-European» (Treitler, 1991, p. 280). Traducción de los autores del artículo. 
estos repertorios, desde una mirada evolutiva, ha dependido de fuentes notacionales (escritura que solo registra los cambios de notas en el devenir musical) para poder determinar continuidades y rupturas en la historia de la música. Los momentos en que las fuentes escritas muestran que las modificaciones en el lenguaje, su uso o sus técnicas, superan las continuidades, se interpretan como un cambio de estilo para la historiografía llamada positivista o tradicional, colaborando en el proceso de empoderamiento de la polifonía frente a otros parámetros musicales.

Sin embargo, es posible encontrar algunos indicios que nos permiten una mirada alternativa. La preocupación especial en el plano teórico por el estudio de la superposición de los sonidos, como también las músicas europeas de tradición popular donde ya existía la práctica del canto a voces, son dos de los casos para comenzar a desandar el camino.

\section{UN PROBLEMA DE FUENTES}

Una de las fuentes principales para explicar el fenómeno de la polifonía la encontramos en los escritos medievales sobre música. Uno de los textos más significativos de la teoría musical medieval es De institutione músico [c. 480-524] (2009), de Boecio escrito como un texto científico-filosófico como parte del desarrollo del conocimiento medieval asociado a las siete artes liberales, dentro de las cuales la música integraba la matheis, o sea, las matemáticas. En este tratado se definen, entre otras cosas, las músicas, los músicos, el sonido. Como parte del desarrollo del conocimiento musical en estos términos, Boecio le dedica el mayor contenido de su obra a la relación entre dos alturas y lo que se considera una consonancia. Basado en los preceptos pitagóricos de la matemática de las distancias entre los sonidos desarrolla cuáles son las relaciones posibles en esa simultaneidad:

La consonancia, de hecho, aunque también la discierne en su juicio el sentido del oído, sin embargo, la sopesa la razón. Cuántas veces, en efecto, dos nervios, uno de ellos más grave, son tensados y pulsados simultáneamente, dan respuesta un sonido en cierto modo entremezclado y agradable; y las dos voces conjuntamente se funden como en una sola cosa; entonces se produce eso que se dice consonancia. Cuando, en cambio, pulsados simultáneamente, cada uno desea ir para su lado y no entremezclan de cara al oído un sonido agradable y unitario, compuesto por los dos, entonces hay disonancia (Boecio, [c. 480-524] 2009, p. 142).

Otro texto en el que se encuentra una descripción acerca de la utilización de la superposición de voces es el libro Etimologíos [627-630] (2004), de Isidoro de Sevilla (560-633). Este no es un libro de música específicamente, pero en él se caracterizan las disciplinas de las artes liberales. 
En el apartado de la música asociada a la voz, describe los conceptos de armonía, sinfonía (consonancia) y diafonía (disonancia):

Armonía es la modulación de la voz y la consonancia o adecuación de varios sonidos. Sinfonía es la combinación proporcionada de la modulación mediante la consonancia de los sonidos graves y agudos que se producen por la voz, el aire o la pulsación. Gracias a ella, las voces agudas y graves se combinan de manera que cualquier disonancia que se produzca molesta al oído. Lo contrario a ella es la Diafonía, es decir, voces en disonancias o discordantes (de Sevilla, [627-630] 2004, p. 437).

Si bien ninguno de los dos textos habla en particular de la práctica musical, es posible entender, en ambos, la distinción entre una consonancia y una disonancia a partir de la escucha. En principio, un primer antecedente para atreverse a sospechar que la superposición de alturas era algo escuchado, común, mucho antes de su supuesta aparición que esgrimen los manuales de historia de la música.

El tratado anónimo datado en el siglo IX, Musico Enchiriodis (anónimo, 1981), es el primero que ofrece una descripción de las prácticas polifónicas aplicables al corpus del canto llano y que dio lugar a los distintos tipos de Organum. En este tratado se desarrollan las técnicas del canto a voces a distancias paralelas de cuartas, quintas y octavas (consideradas las consonancias de la época tanto por su estabilidad como intervalos justos como por su proporción matemática). También están descritas las técnicas de los cantos a voces nota contra nota (punctum contra punctum). No se encuentran partituras de estas técnicas sino una explicación de cómo se debían llevar a la práctica: de oído.

Esto nos lleva a preguntarnos si este manuscrito está realmente describiendo una técnica nueva o simplemente compila una tradición oral e improvisatoria ya conocida. Esta segunda hipótesis destierra la noción de que este documento es la evidencia del nacimiento de la polifonía y refuta su pretendida exclusividad occidental:

Si fechamos como muy tarde el Musica Enchiriodis alrededor del año 850, nos queda un lapso de más de cuatrocientos años en los que sabemos que la polifonía en cuartas y quintas jugó un rol prominente. Y, debemos agregar, el Musica Enchiriadis trata la polifonía como algo que ya era familiar en su época (Bukofzer, 1940, p. 31). ${ }^{2}$

2 «If we date the Musica Enchiriadis at about 850, at the latest, we are left with a span of more than four hundred years in which we know positively that fourths and fifths played a prominent r61e in polyphony. And, it should be added, the Musica Enchiriadis treats of polyphony as of something already familiar» (Bukofzer, 1940, p. 31). Traducción de los autores del artículo. 


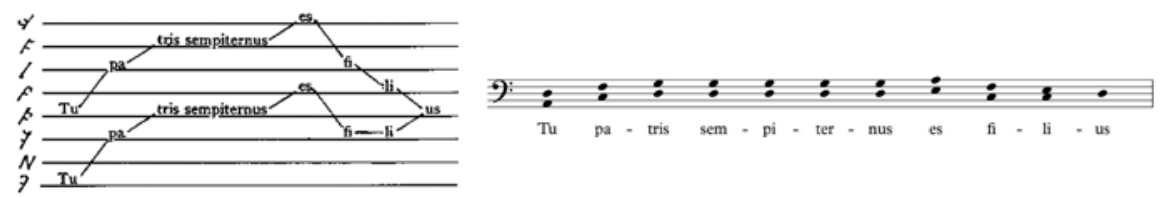

Figura 1. Organum paralelo a la cuarta

En esta imagen [Figura 1] vemos cómo se ejemplifica el Organum paralelo a la cuarta. En la descripción dentro del tratado se encuentra la siguiente leyenda: «Es así, de hecho, que dos o más voces juntas sólo de forma mesurada y con adecuada lentitud, como es propio en estos cantos, se verá nacer de allí sonidos unidos armoniosamente» (Anónimo, [siglo IX] 1981, p. 38). ${ }^{3}$

Entonces, los registros polifónicos de la época ¿son creaciones nuevas o dan cuenta de prácticas que se llevaban a cabo desde mucho tiempo antes, tanto dentro de la Iglesia como en las músicas populares y cortesanas?

Richard Taruskin (2005) propone una posible respuesta a estas incógnitas:

Dado que no existe ningún período en el cual las prácticas de la música europea desconocieran la polifonía, no podemos decir que ésta última se originó en la tradición europea. Escrita o no, siempre estuvo ahí. Como pasa con cualquier otro tipo de música, su ingreso a las fuentes escritas no constituye ningún «acontecimiento» en su historia. (El acontecimiento, como tal, tiene que ver con nuestra historia, que es la historia de lo que somos capaces de conocer). Y de igual modo, no existió un momento en el cual la polifonía haya suplantado a la «monofonía» en la historia de la música occidental, sobre todo si reconocemos que la monofonía fue solamente un estilo de notación y no necesariamente un estilo de realización musical (p. 193). ${ }^{4}$

\section{ANTECEDENTES DE POLIFONÍA EN LA EDAD MEDIA}

Lejos de los desarrollos técnicos y de la especulación analítica -y, por ende, de la producción de registros escritos en partitura-, la polifonía

3 «Sic enim duobus aut pluribus in unum canendo modesta dumtaxat et concordi morositate, quod suum est huius meli, videbis suavem nasci ex hac sonorum commixtione concentum» (Anónimo, [siglo IX] 1981, p. 38). Traducción de los autores del artículo.

4 «Since there is no period in which the known practices of European music did not include polyphony, polyphony cannot be said to have an origin in the European tradition. Written or not, it was always there. As with any other kind of music, its entry into written sources was not any sort of "event" in its history. (The event, as such, was in our history, the history of what we are able to know.) And by the same token, there is no point at which polyphony completely supplanted "monophony" in the history of Western music, especially if we recognize that monophony is only a style of notation, not necessarily a style of music» (Taruskin, 2005, p. 193). Traducción de los autores del artículo. 
floreció en la música popular. Hay registros de músicas populares polifónicas desde antes del siglo XII, por medio de relatos de viajeros que describen los métodos y la fenomenología del canto a voces. Manfred Bukofzer (1940) realiza un análisis sobre un Tvísöngur, un tipo de canto paralelo a dos voces que aún hoy tiene vigencia como una tradición anglo-báltica y que, por sus características musicales, resulta muy similar al Organum paralelo de quintas; de hecho, tanto el Tvísöngur como el Organum medieval se cantan pausadamente a una velocidad lenta.

En esta música la línea melódica principal es duplicada por otra en un intervalo de quinta justa, superior o inferior de acuerdo a las posibilidades vocales de los cantantes; cuando la duplicación llega a un registro muy exigido, se cruza con la voz principal en un unísono para retomar la duplicación pero una quinta justa por debajo. Los unísonos también funcionan como nota de inicio de frases y de conclusión, como nota de llegada.

Dentro de estas tradiciones polifónicas se destaca el Gymel (nombre de raíz latina [contus gemellus] que significa canto gemelo). Estas canciones, cuyo registro notacional más antiguo data de finales del siglo XIII, trabajan la misma idea de duplicación paralela no estricta, con la particularidad de utilizar el intervalo de tercera como sonoridad consonante.

En la siguiente imagen [Figura 2] podremos ver la transcripción del Himno a San Magnus "Nobilis humilis». La preponderancia del intervalo de tercera diatónica es notable a lo largo de toda la obra y los unísonos significan un punto de llegada o de partida que genera segmentaciones formales (con la excepción de la quinta nota del tercer sistema y la sexta nota del tercer sistema, esos unísonos no articulan forma en la obra). Los escasos intervalos de cuarta y de quinta son utilizados en dos finales de frase para facilitar el movimiento contrario en la cadencia. De esta forma, mediante la aceleración de la voz grave, quedan a una distancia interválica de quinta y luego compensan esa distancia para concluir la frase musical en el unísono. Por último, hay una disonancia de segunda que se genera luego de un salto que es de quinta justa en la voz grave y de cuarta justa en la voz aguda que, mediante la aceleración de la voz superior, vuelve al intervalo de tercera.

En la partitura se ven encerrados dentro de los rectángulos amarillos los unísonos y dentro del verde el intervalo de segunda y su resolución ascendente a una tercera; mientras que dentro de los naranjas, la preparación del proceso cadencial por medio de la apertura en cuarta y quinta.

Esta canción está cantada en latín sobre texto religioso devocional pero su producción es del ámbito secular. Como menciona Bukofzer (1940), «no debemos cometer el error de pensar que durante la Edad Media todo lo religioso no es popular ni tampoco que todo lo secular es popular» (p. 36). ${ }^{5}$

5 «We must not make the mistake of assuming that, in the Middle Ages, everything religious is not popular, or that everything secular is popular» (Bukofzer, 1940, p. 36). Traducción de los autores del artículo.

6 Clang 


\section{Nobilis humilis}

Magnushymnen
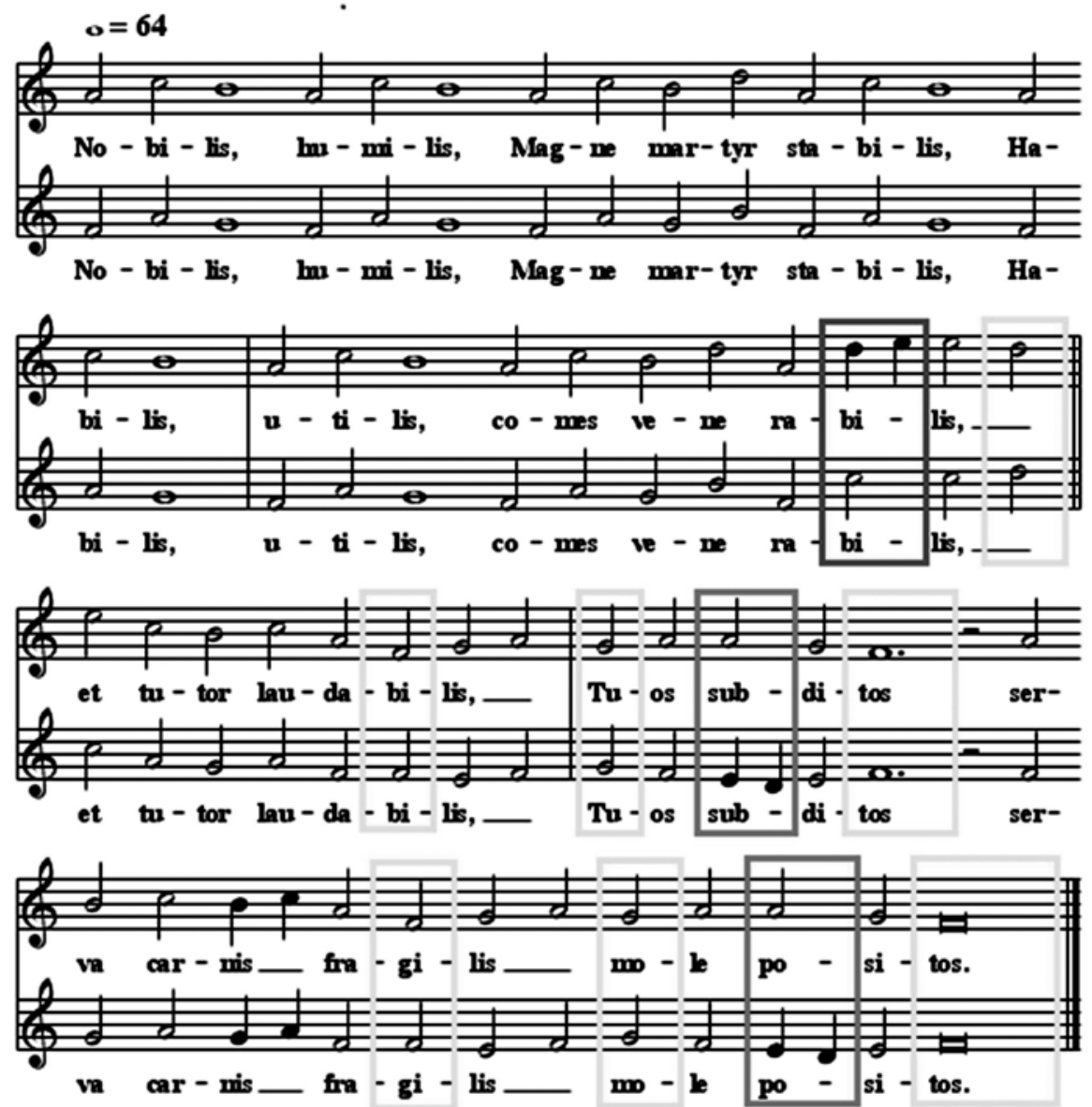

Figura 2. Transcripción del Himno a San Magnus «Nobilis humilis»

Los préstamos y los intercambios entre músicos de todos los ámbitos de producción eran una posibilidad en el mundo medieval; después de la celebración de la Santa Misa, la feligresía en su conjunto celebraba entonando y danzando canciones seculares en el patio de la iglesia. Las técnicas utilizadas en una práctica musical específica podían ser tomadas y reelaboradas por músicos de otro ámbito. Así la polifonía con terceras paralelas puede haber surgido como técnica de amplificación en las islas británicas o en la región de Escandinavia, o en ambas al mismo tiempo. Luego se abrió 
camino por el continente europeo a partir de la guerra de los cien años y la ocupación inglesa de territorio galo, ampliando el repertorio de sonidos consonantes en la cultura occidental.

Inevitablemente, el tipo de música que se escuchaba fuera de la iglesia comenzó a influir sobre la que se escuchaba dentro. La incorporación de instrumentos en el culto impuso al compositor de música religiosa las técnicas establecidas que se empleaban en la música secular, del mismo modo que los ritmos y los estilos melódicos de la música secular parecen haber influido en el compositor de música religiosa (Raynor, 1986, p. 10).

\section{CONCLUSIÓN}

Partimos de la hipótesis de que los juicios de valor sociales, institucionales e individuales surgen, en gran medida, de supuestos naturalizados sobre la cultura, la música y la función de los artistas, y entendemos que en el proceso de construir la cultura occidental la polifonía sirvió para representar dos rasgos considerados como positivos en el mundo civilizado: el carácter reglado de la técnica polifónica y la individualización del hacer musical en la imagen del compositor. Era de esperar que ante la necesidad de ampliar el objeto de estudio de la historia de la música a aquellos repertorios, actores y geografías escindidos de ese paradigma - como la música popular- surgieran problemáticas asociadas a los grandes conceptos que han sostenido el relato historiográfico hegemónico.

¿Qué debería cambiar en nosotros a partir de comprender que la polifonía y la armonía siempre estuvieron ahí, en todos lados, en todas las épocas, en todos los pueblos? La música fue una de las herramientas de la conquista, una forma de imponer una concepción de tiempo y de orden que no son y nunca fueron naturales, sino una construcción simbólica de largo aliento:

Para cumplir con la función de «humanar» a los indios, los pueblos en los que estaban congregados debían ser urbanos, o sea civilizados. Las distintas modalidades de orden de las que carecían «en su gentilidad» debían estar incorporadas a la vida y al espacio urbano. Las prácticas musicales, extraordinariamente importantes en estos centros según los cronistas, contribuían poderosamente a construir ese orden. Lejos de ser un mero auxilio para la evangelización, eran potentes instrumentos para definir la noción de lo urbano. Las tradiciones pitagórica y platónica (la música como orden perfecto y la música como medio para formar al hombre) confluían en las mentes de los doctrineros (Waisman, 2005, p. 3). 
Como latinoamericanas y latinoamericanos, como músicos y docentes, tenemos la responsabilidad de conocer las tradiciones que entran en conflicto en el -todavía vigente- proceso de conquista. La cultura occidental es parte de nuestro ADN simbólico, como también lo son el canto grupal africano, las músicas complejas de las culturas indígenas y todos los productos de este proceso conflictivo de mestizaje y transculturación.

Tal vez, en el estudio de los repertorios previos al establecimiento del canon y, por lo tanto, previos a la cristalización del lenguaje armónico-tonal, se encuentren respuestas de cuánto de lo establecido en el relato historiográfico hegemónico es una mera construcción disciplinatoria y cuánto es una aproximación a la realidad social. Es nuestra oportunidad para poder generar nuestros propios paradigmas para el estudio de las músicas que nos ocupan y, de una vez por todas, revisar ese pasado que nos hicieron desear y que no nos permitió contemplar las características identitarias de las producciones musicales de nuestro entorno.

\section{REFERENCIAS}

Anónimo. [s.IX] (1981). Musica enchiriadis. En H. Schmid (Ed.), Musica et scolica enchiriadis una cum aliquibus tractotulis adiunctis. Munich, Alemania: Bayerische Akademie der Wissenschaften, Veröffentlichungen der Musikhistorischen Kommission.

Boecio. [c.480-524] (2009). Sobre el fundamento de la música. Madrid, España: Gredos.

Bukofzer, M. (1940). Popular Polyphony in the Middle Ages. The Musical Quarterly, 26(1), 31-49.

de Sevilla, I. [627-630] (2004). Etimologías. Madrid, España: Biblioteca de autores cristianos.

Grout, D. (1980). Historia de la Música occidental. Vol 1. Madrid, España: Alianza.

Raynor, H. (1986). Una Historia social de la Música. Madrid, España: Siglo XXI.

Taruskin, R. (2005). The Oxford history of western music. Volume 1: The earliest notations to the sixteenth century. Oxford, Reino Unido: Oxford University Press.

Treitler, L. (1991). The Politics of Reception: Tailoring the Present as Fulfilment of a Desired Past. Journal of the Royal Musical Association, 116(2), 280-298.

Waisman, L. (2005). La música en la definición de lo urbano: los pueblos de indios americanos. En Música y cultura urbana en la edad moderno (pp. 159-176). Valencia, España: PUV. 